\title{
Adherence of surgeons to surgical prophylaxis guidelines
}

\author{
Alshehri Ibrahim M. ${ }^{1}$, Albishry Ibraheem M. ${ }^{2}$, Alharthi Khuwailid R. ${ }^{3}$, Al Qarni Bader A..* \\ ${ }^{1}$ Inpatient Pharmacy Supervisor, Rabigh General Hospital, Jeddah, ${ }^{2}$ Rabigh General Hospital, \\ Pharm.,D ${ }^{3}$ King Abdullah Hospital, Bishah, BPharm, Pharm., ${ }^{4}$ Al-Thagar General Hospital, Jeddah, \\ BPharm, Pharm.
}

Corresponding author: Al Qarni, Bader Ayed, Training and Education Section Supervisor, Al-Thagar General Hospital, Jeddah, BPharm, PharmD, MClinPharm. Be.cl.phar@gmail.com.

\begin{abstract}
Background: surgical site infections (SSIs) are microbial contamination of the surgical wound during a period of one month that could result in major post-operative morbidity and mortality rates. Objectives: this study aimed to identify the adhesion of surgeons to antibiotics prophylaxis guidelines at Kingdom of Saudi Arabia (KSA). Methods: this study included 180 adult subjects who were scheduled to undergo major surgeries in the hospital. The data of the patients were collected from the surgical wards and day care unit. Results: most of the included surgeons showed no error during pre, intra and post operative duration as give the required antibiotics and didn't give the non-require antibiotics. The preoperative adherence of surgeons as most of the surgeons (73.9\%) followed the prophylactic measures that included correct choice, indications, dosage and duration. Most of the surgeons $(76.1 \%)$ followed the prophylactic measures including correct choice, indications, dosage and duration during intra-operative period. The majority of the surgeons $(75 \%)$ followed the prophylactic measures including correct choice, indications, dosage and duration during post-surgical duration. Conclusion: The level of surgeon's adherence to antibiotic prophylactic guidelines was efficient among most of surgeons regarding the proper choice of antibiotic, duration, timing and indication. However, these results differ from other available studies, this study showed a good sign for application of antibiotic prophylactic measures in KSA hospitals. Further studies should be conducted to increase the knowledge and adherence of surgeons all over KSA.
\end{abstract}

Keywords: adherence, prophylactic measures, antibiotic prophylaxis guidelines, surgeons, KSA, 2018.

\section{Introduction}

Surgical site infections (SSIs) are microbial contamination of the surgical wound during a period of one month. SSIs could result in major post-operative morbidity and mortality rates that increases the costs of treatment on populations and health authorities ${ }^{(\mathbf{1}, 2)}$. The SSI annual prevalence in the United States was about $1.07 \%$ resulting in 8000 deaths every year with more than 10 billion dollars for treatment (3). Also, in the United Kingdom, SSI was responsible for increasing the length of the hospital stay from 5-17 days and extra cost for each case by about 3394 dollars ${ }^{(4,5)}$. About $40 \%$ of surgical infections were found to be SSIs ${ }^{(6)}$ thus prevention and implementing of antibiotic prophylaxis projects could reduce the rates of SSIs which in turn would decrease hospital stay, ICU admission and costs for further treatment ${ }^{(7-10)}$. The antibiotic prophylaxis programs are defined as the administration of antibiotic medications before, during or after the surgery to decrease the risk of infection and its consequences ${ }^{(11,12)}$. They were recommended for clean, contaminated as well as dirty procedures to avoid specific criteria of risk factors for infection ${ }^{(12-15)}$.At first, the type of surgery must be determined then implanting a protocol for proper prophylactic program. Also, popper time, efficiency, advantages and complications must be taken into consideration before, during and after the surgery. The greater the adhesion to the surgical antibiotic prophylaxis would significantly decrease the rates of anaphylactic shock and diarrhea induced by antibiotic usage. Another aspect that necessitates adhesion of surgeons to antibiotic prophylaxis programs is to reduce the resistance pattern of microbes to antimicrobial agents. This study aimed to identify the adhesion of surgeons to antibiotics prophylaxis guidelines.

\section{Rational and hypothesis:}


The antibiotic prophylaxis guidelines are the most effective programs for prevention of surgical infections during and after surgery. The lack of knowledge, education and adhesion to these programs would increase the risks of SSI which would increase the costs of treatment, increase the mortality and morbidity rates as well as admission to ICU and the length of hospital stay. Assessing the practice and adherence pattern will improve the knowledge and practice of surgeons and overcome the increased risks of surgery infections.

\section{Objectives:}

- General objectives:

1- Assessing the adhesion of surgeons to antibiotics prophylaxis guidelines.

- Specific objective:

1- Increasing the attention of Saudi surgeons toward the usage of antibiotic prophylaxis guidelines.

\section{Methods:}

\section{Study design:}

An observational cross sectional hospital based survey.

\section{Setting:}

The study was carried out at the Rabigh General Hospital from January 2018 to March 2018.

\section{Study population:}

This study included adult subjects who were scheduled to undergo major surgeries in the hospital. The exclusion criteria were infant's surgeries, cancer, refusal of the patients and contaminated surgeries.

\section{Study population and sample size:}

With regards to the number of surgeries in the department during the last 12 months a sample of 180 surgeries were chosen to participate in the study during the study period.

\section{Study tools and data collection:}

The data of the patients were collected from the surgical wards and day care unit. All the data from the patient's files were collected and divided into three main parts which include preoperative, intra-operative and post-operative antibiotic prophylactic measure which were compared with the international programs. Also, the main outcome measures will include the suitability of indicted prophylactic antibiotic, the antibiotic choice, dosage of administration, timing and duration.

\section{Limitation of the study:}

- There is a lack of studies conducted in KSA about this subject. Limitations of time, number of included cases and access to all patient's files.

\section{Ethical considerations:}

A written approval was provided from the supervisors regarding the aim of the study. The questionnaire will be validated by 3 supervisors. An informed contest was given by all participants who approved to take part in the study.

\section{Statistical analysis:}

The data processing was done using SPSS for windows (version 22). The descriptive variables will be shown as frequencies and percentages.

\section{Results:}

Tables 1 and 2 showed the demographic characteristics of the included patients including distribution of age and gender (Figures 1 \&2). The studied patients were distributed according to their hospital stay as shown in table. 3 and figure 3.

Table 1: distribution of the studied group regarding their age

\begin{tabular}{|l|c|c|}
\hline & Number & Percent \\
\hline$>40$ yrs. & 54 & 29.9 \\
\hline $40-50$ & 44 & 24.6 \\
\hline$>50$ yrs. & 82 & 45.5 \\
\hline Range & \multicolumn{2}{|c|}{$26-67$} \\
Mean & \multicolumn{2}{|c|}{48.3} \\
S.D. & \multicolumn{2}{|c|}{12.6} \\
\hline
\end{tabular}




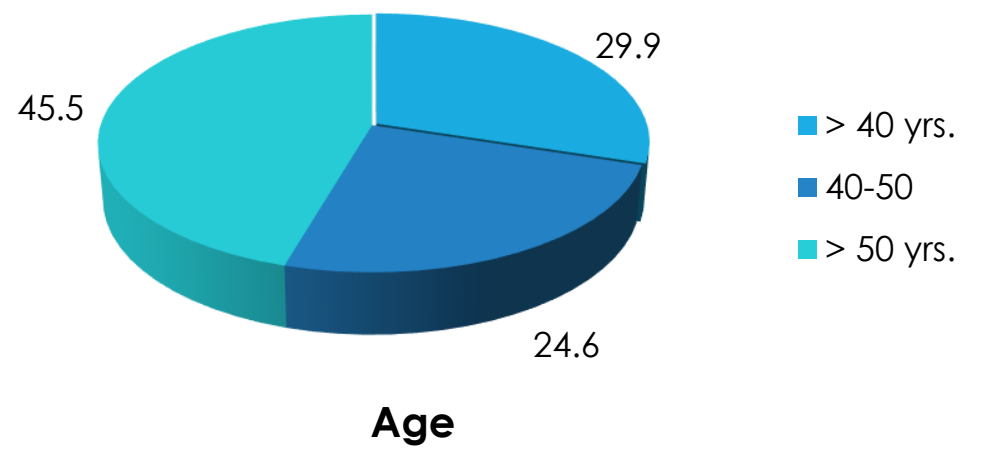

Figure 1: distribution of the studied group regarding their age

Table 2: distribution of the studied group regarding their gender

\begin{tabular}{|l|c|c|}
\hline Gender & Number & Percent \\
\hline Male & 90 & 50.0 \\
Female & 90 & 50.0 \\
Total & 180 & 100.0 \\
\hline
\end{tabular}

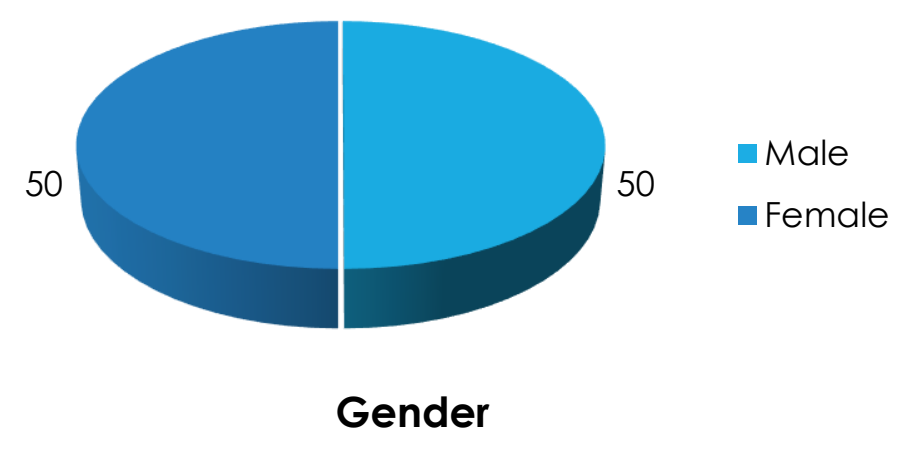

Figure 2: distribution of the studied group regarding their gender

Table 3: distribution of the studied group regarding their hospital stay (days)

\begin{tabular}{|l|c|c|}
\hline & Number & Percent \\
\hline $2-3$ & 51 & 28.3 \\
\hline $4-6$ & 74 & 41.1 \\
\hline$>7$ & 55 & 30.6 \\
\hline Total & 180 & 100.0 \\
\hline
\end{tabular}




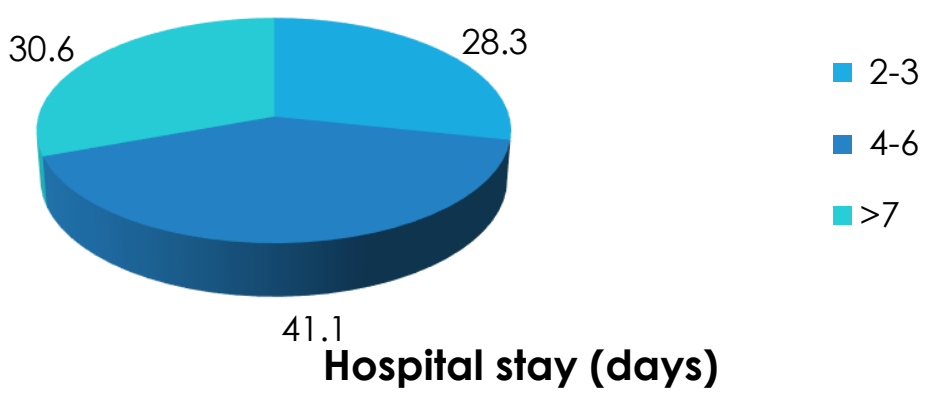

Figure 3: distribution of the studied group regarding their hospital stay (days)

\section{- Type of surgery:}

The patients were distributed according to the type of surgery as most of the subjects were having upper and lower abdominal surgery (28.9\%) followed by $24.4 \%$ for gynecological surgeries then emergency surgeries (16.7\%), 15.6\% for head and neck surgeries and q4.4\% for orthopedic surgeries (Table 4 and figure 4$)$.

Table 4: distribution of the studied group regarding their surgery type

\begin{tabular}{|l|c|c|}
\hline & Number & Percent \\
\hline Upper and lower abdomen & 52 & 28.9 \\
Orthopedic & 26 & 14.4 \\
Head and neck & 28 & 15.6 \\
Emergency & 30 & 16.7 \\
Gynecological & 44 & 24.4 \\
Total & 180 & 100.0 \\
\hline
\end{tabular}

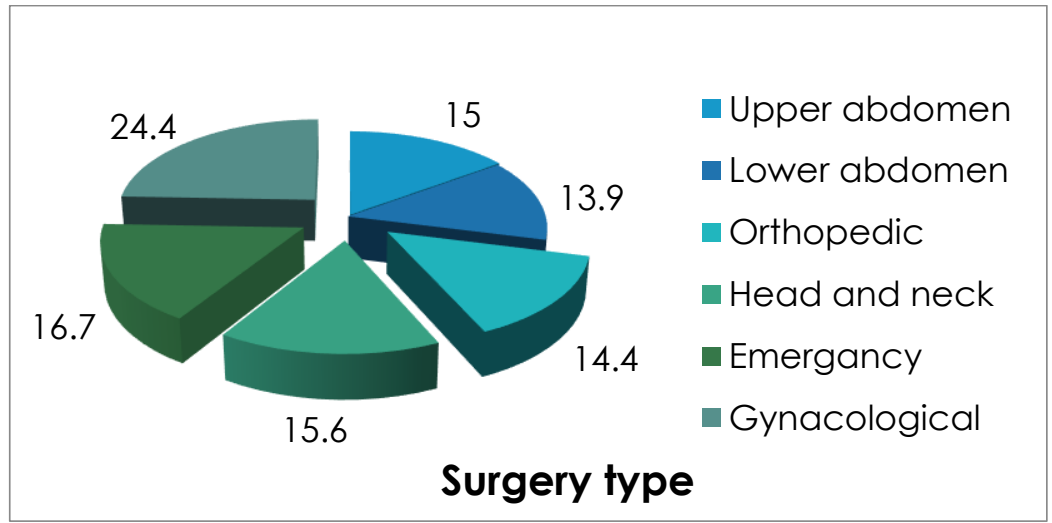

Figure 4: distribution of the studied group regarding their Surgery type

- Surgery class:

Most of the included surgeries were clean $(91.7 \%)$ and $8.3 \%$ were contaminated (Table 5and figure $5)$.

Table 5: distribution of the studied group regarding their surgery class

\begin{tabular}{|l|c|c|}
\hline & Number & Percent \\
\hline Clean & 165 & 91.7 \\
Contaminated & 15 & 8.3 \\
Total & 180 & 100.0 \\
\hline
\end{tabular}




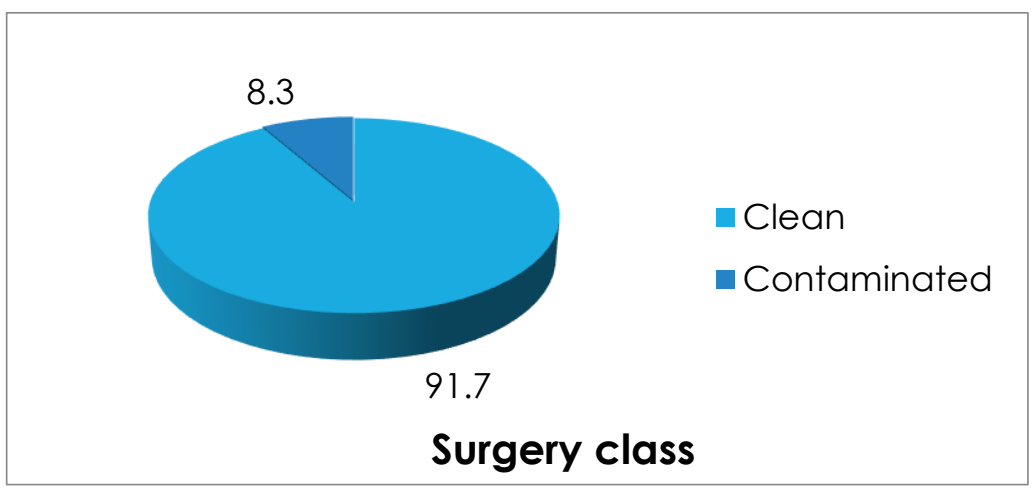

Figure 5: distribution of the studied group regarding their surgery class

- Pre-operative prophylactic measures:

Most of the included surgeons showed no error among $73.9 \%$ who give the required antibiotics and $5 \%$ among those who don't require antibiotics. Only $21 \%$ of errors were shown as $15 \%$ administrated non required antibiotics and $6.1 \%$ of surgeons didn't give the required antibiotic (Table .6, figure. 6) Table 6: distribution of the studied group regarding their pre operative prophylactic measures

\begin{tabular}{|l|c|c|}
\hline & Number & Percent \\
\hline No error & & \\
\hline Required and administrated & 133 & 73.9 \\
Not required and not administrated & 9 & 5.0 \\
Error: & & \\
Not required but administrated & 27 & 15.0 \\
Required but not administrated & 11 & 6.1 \\
Total & 180 & 100.0 \\
\hline
\end{tabular}

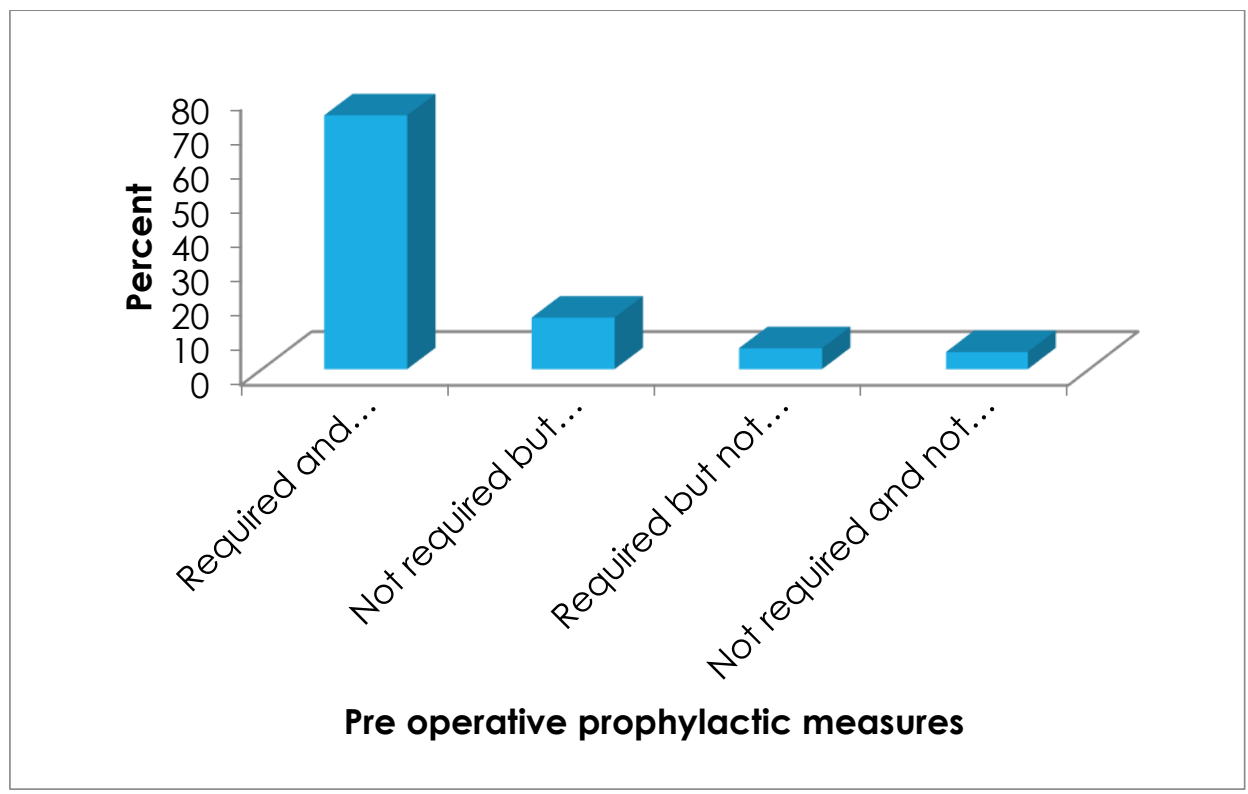

Figure 6: distribution of the studied group regarding their pre operative prophylactic measures Intraoperative prophylactic measure:

Most of the surgeons showed no error during the surgery as $76.1 \%$ of patients were administrated the required doses, while the intraoperative error was $11.7 \%$ among patients. On the other hand $10 \%$ of the patients were not detectable about their intraoperative prophylactic measures. 
Table 7: distribution of the studied group regarding their intra-operative prophylactic measures

\begin{tabular}{|l|c|c|}
\hline No error & Number & Percent \\
\hline Required and administrated & 137 & 76.1 \\
Not required and not administrated & 4 & 2.2 \\
Error & & \\
Not required but administrated & 14 & 7.8 \\
Required but not administrated & 7 & 3.9 \\
Total & 180 & 100.0 \\
\hline & & \\
\hline
\end{tabular}

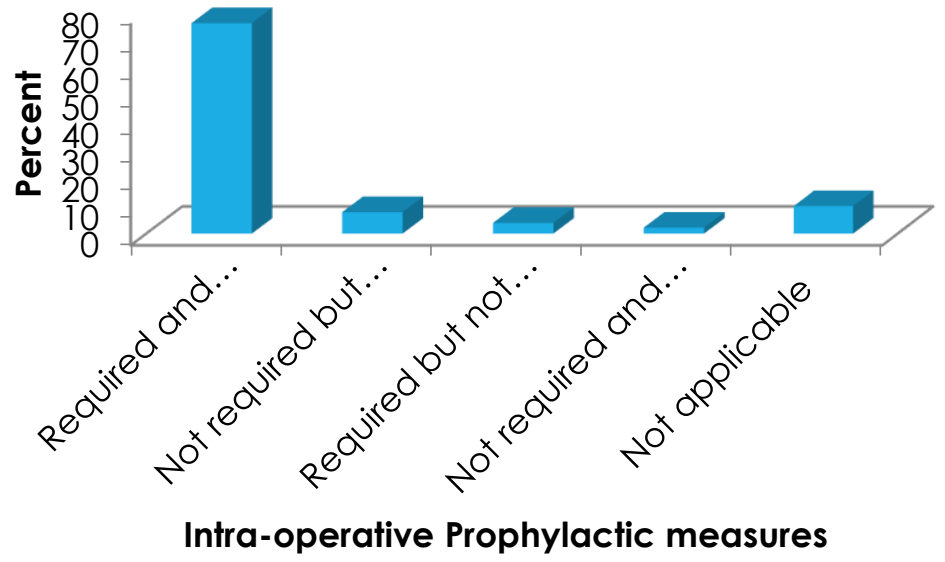

Figure 7: distribution of the studied group regarding their Intra-operative Prophylactic measures

- Postoperative prophylactic measures:

Most of the surgeries showed no error among $75 \%$ and $3.3 \%$ of patients but $16.7 \%$ of patients were administrated non required doses of antibiotics and $5 \%$ were not administrated their required antibiotic doses.

Table (8): Distribution of the studied group regarding their Post operative Prophylactic measures

\begin{tabular}{|l|c|c|}
\hline No error & Number & Percent \\
\hline Required and administrated & 135 & 75.0 \\
Not required and not administrated & 6 & 3.3 \\
Error & & \\
Not required but administrated & 30 & 16.7 \\
Required but not administrated & 9 & 5.0 \\
Total & 180 & 100.0 \\
\hline
\end{tabular}




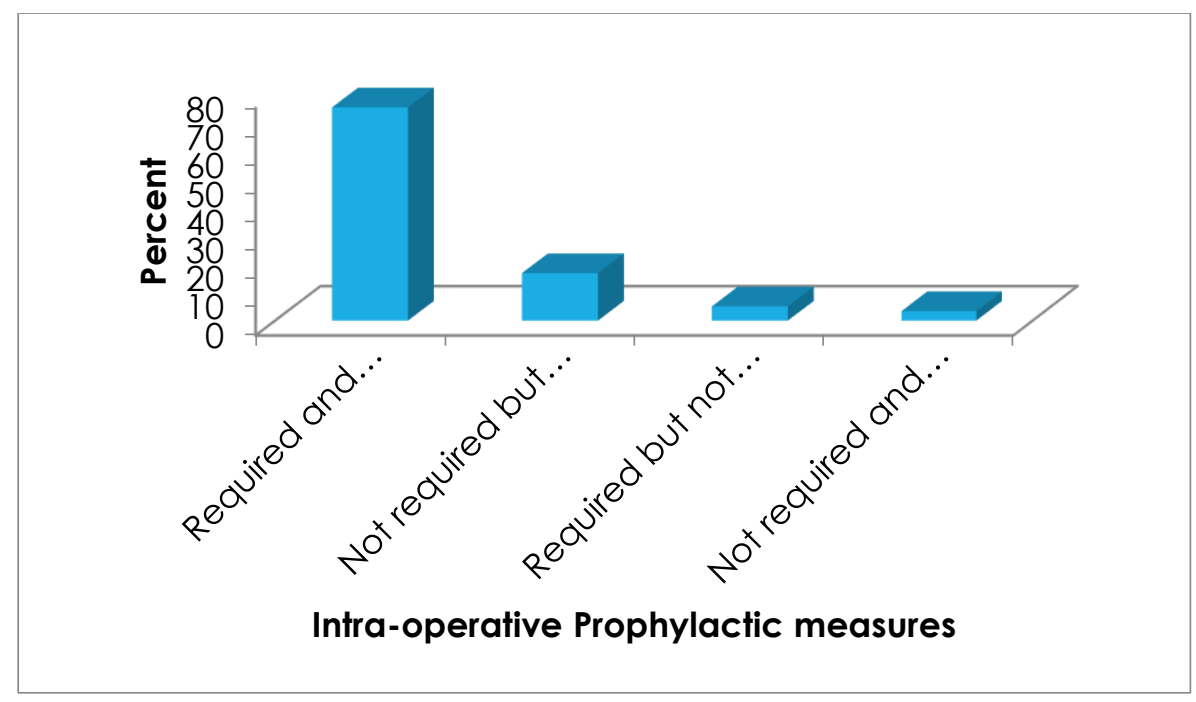

Figure 8: distribution of the studied group regarding their Post operative Prophylactic measures

\section{Antibiotic choice:}

Table 9 showed that the most commonly used antibiotic were cefixime and metronidazole followed by Celphaosprorin and penicillin (Table 9 and figure 9). The dosage of administration were once or twice among most of the subjects (Table10 and figure 10)

Table 9: distribution of the studied group regarding their antibiotic choice

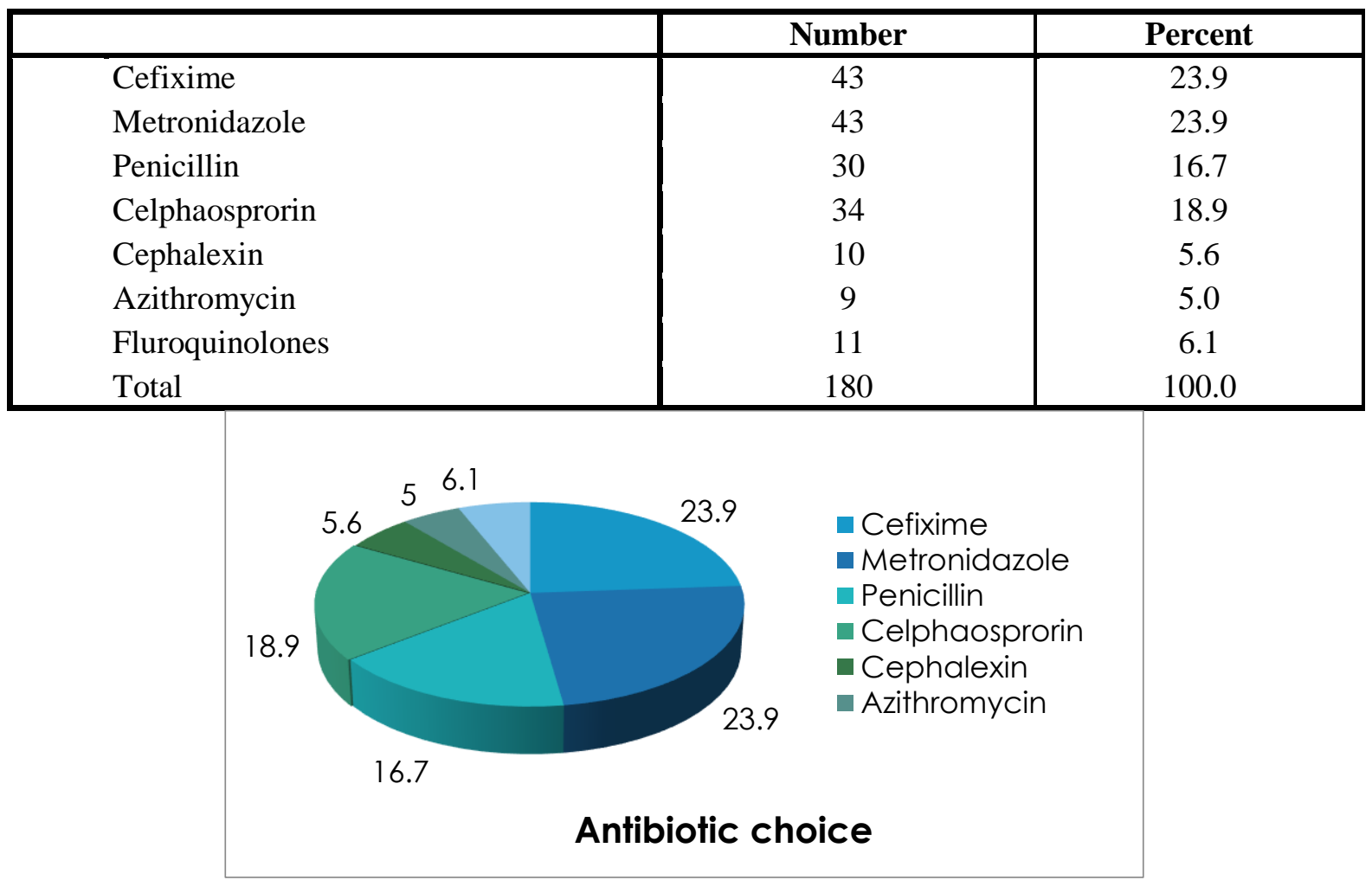

Figure 9: distribution of the studied group regarding their antibiotic choice 
Table 10: distribution of the studied group regarding their dosage of administration

\begin{tabular}{|l|c|c|}
\hline & Number & Percent \\
\hline Once & 89 & 49.4 \\
\hline Two & 80 & 44.4 \\
\hline Three & 11 & 6.1 \\
\hline Total & 180 & 100.0 \\
\hline
\end{tabular}

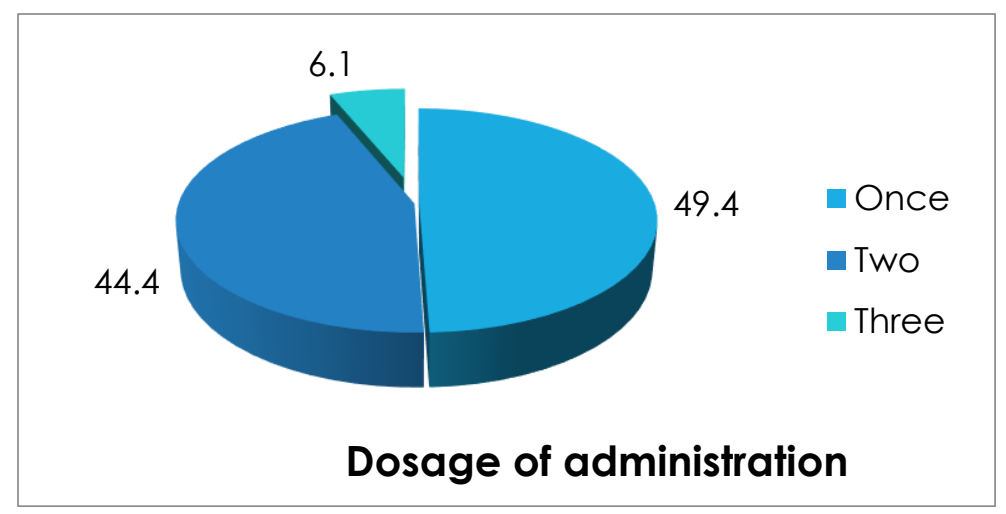

Figure 10: distribution of the studied group regarding their dosage of administration

Preoperative adherence of surgeons:

Table 11 showed the preoperative adherence of surgeons as most of the surgeons (73.9\%) followed the prophylactic measures including correct choice, indications, dosage and duration, $4.4 \%$ followed the correct choice and dosage while $21.7 \%$ followed only the correct choice.

Table 11: distribution of the adherence pattern among the surgeons: pre-operative

\begin{tabular}{|l|c|c|}
\hline & Number & Percent \\
\hline Correct choice, indications, dosage and duration & 133 & 73.9 \\
Correct choice and dosage & 8 & 4.4 \\
Correct choice & 39 & 21.7 \\
Total & 180 & 100.0 \\
\hline
\end{tabular}

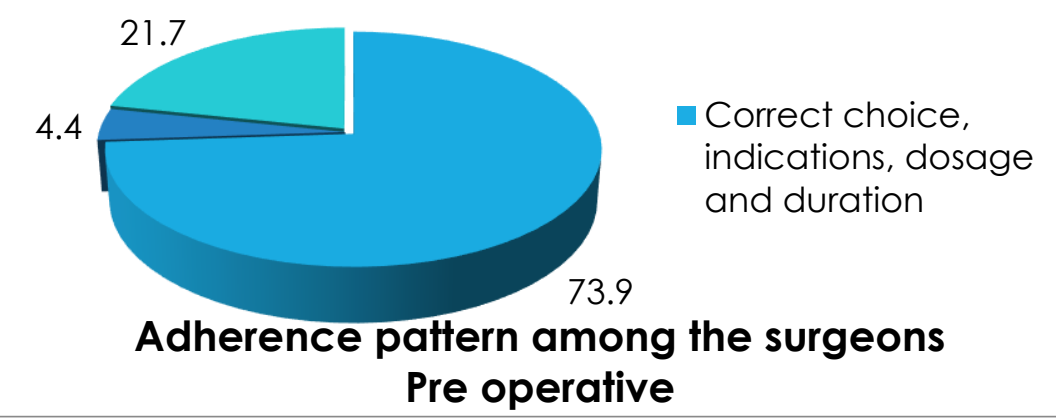

Figure 11: distribution of the studied group regarding their adherence pattern among the surgeons Pre-operative

- Intraoperative adherence:

Most of the surgeons (76.1\%) followed the prophylactic measures including correct choice, indications, dosage and duration, 3.9\% followed the correct choice and dosage while $10 \%$ followed only the correct choice and $10 \%$ were not applicable. 
Table 12: distribution of the adherence pattern among the surgeons: intra-operative

\begin{tabular}{|l|c|c|}
\hline & Number & Percent \\
\hline Correct choice, indications, dosage and duration & 137 & 76.1 \\
Correct choice and dosage & 7 & 3.9 \\
Correct choice & 18 & 10.0 \\
Not applicable & 18 & 10.0 \\
Total & 180 & 100.0 \\
\hline
\end{tabular}

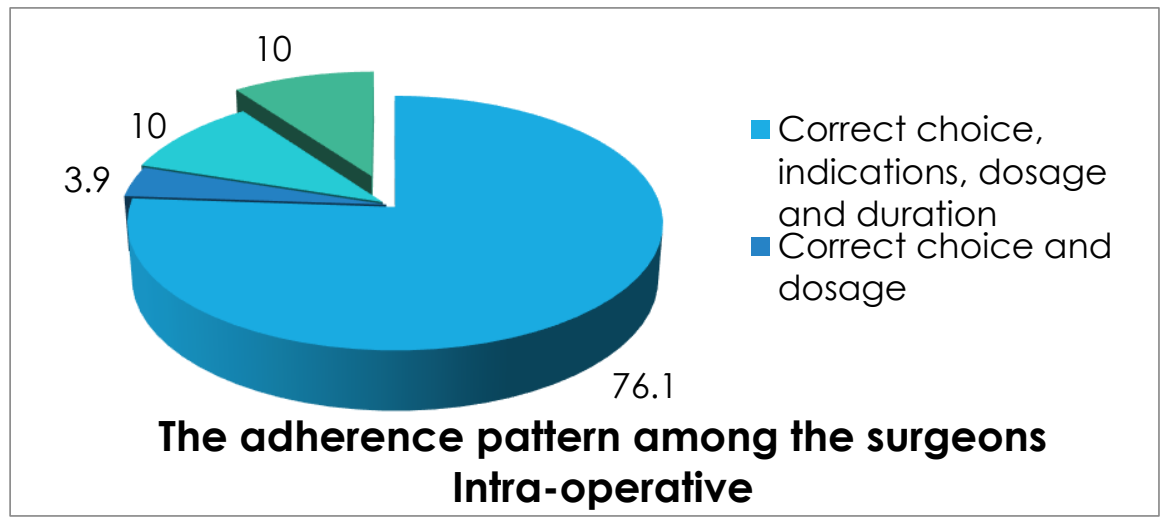

Figure 12: distribution of the adherence pattern among the surgeons: intra-operative Post-operative adherence:

The majority of the surgeons $(75 \%)$ followed the prophylactic measures including correct choice, indications, dosage and duration, $10.6 \%$ followed the correct choice and dosage while $14.4 \%$ followed only the correct choice.

Table 13: distribution of the adherence pattern among the surgeons: post-operative

\begin{tabular}{|l|c|c|}
\hline & Number & Percent \\
\hline Correct choice, indications, dosage and duration & 135 & 75.0 \\
Correct choice and dosage & 19 & 10.6 \\
Correct choice & 26 & 14.4 \\
Total & 180 & 100.0 \\
\hline
\end{tabular}

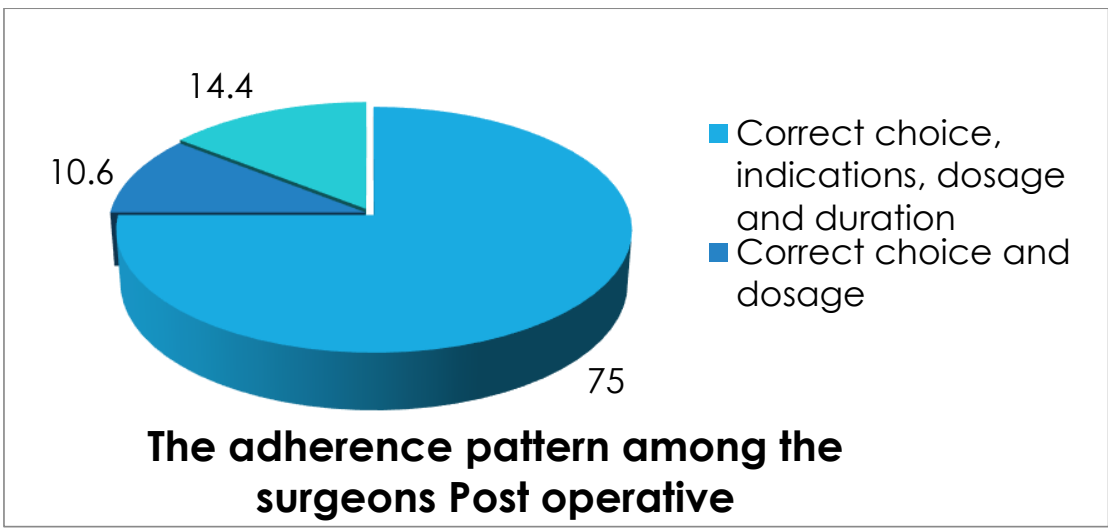

Figure 13: distribution of the adherence pattern among the surgeons post-operative 


\section{Discussion}

The surgical site infection is considered one of the most common risk factors for nosocomial infections resulting in high mortality rates ${ }^{(\mathbf{1 6})}$. The antibiotic prophylactic measures pre, intra and post-surgery could reduce the morbidity and mortality related infections ${ }^{(17,18)}$. A little is known about the adherence of surgeons to American Society of Health-System Pharmacists Surgical Antibiotic Prophylaxis Guidelines in KSA. This study showed good rates of adherence to prophylactic procedures among most of the surgeons during the pre, intra and post-surgical procedures. In Tokyo, the adherence rates to the antibiotic selection were high ranging from $53-84 \%$ and the adherence to the timing and duration was lower but still high reaching to $68 \%{ }^{(19)}$. Stimulatingly, in France, about $49 \%$ of surgeons were adherent to the prophylactic measures for a period of two years (20). However, these results were in contrast of other studies that showed poor rates of prophylactic guidelines adherence ${ }^{(\mathbf{1 1}, 21)}$. Also, other studies have shown low levels of adherence among surgeons and this could be attributed to ignorance of the prophylactic measures and improper over-prescription (22, 23). Another study showed a low level of adherence to all the guidelines aspects (28\%) among Dutch hospitals ${ }^{(24)}$. Higher rate of non-commitment to proper antibiotic, dosage, duration and timing selection which were contract to our results as the levels of errors were not that high and the level of compliance to prophylactic measures was good enough among most of the subjects ${ }^{(9}$, 25-27). The same results were found in Canada with a low adherence levels as only $32 \%$ of patients received the recommended prophylaxis (28). Supplementary, the adherence to the antibiotic prophylaxis duration was inappropriate among $65 \%$ of the surgeries ${ }^{(29)}$. The present study showed that the most commonly used antibiotic were cefixime and metronidazole. The dosage of administration was once or twice among most of the subjects. The same results were reported in Abdel-Aziz et al ${ }^{(9)}$ study shows that cefazolin $(44.6 \%)$ was the most frequently used antibiotic and other studies declared that cephalosporin antibiotics were the preferred choice in most of surgical procedures (30). Also, cephalosporin and ceftriaxone were used as the drug of choice in most of studies but excessive use of ceftriaxone could result in antibiotic resistance $\mathbf{( 1 1 , 2 1 )}$.

\section{Conclusion}

The level of surgeon's adherence to antibiotic prophylactic guidelines was efficient among most of surgeons regarding the proper choice of antibiotic, duration, timing and indication. However, these results differ from other available studies, this study showed a good sign for application of antibiotic prophylactic measures in KSA hospitals. Further studies should be conducted to increase the knowledge and adherence of surgeons all over KSA.

\section{Ethical considerations:}

A written approval was provided from the supervisors regarding the aim of the study. The questionnaire was validated by 3 supervisors. An informed contest was given by all participants who approved to take part in the study.

\section{References}

1.Centers for Disease Control and Prevention (CDC) (2017): Surgical site infection (SSI) event. Avialable at: https://wwwcdcgov/nhsn/pdfs/pscmanual/9psc ssicurrentpdf.

2.Gabrielsen JD (2002): Sabiston Textbook of Surgery. $16^{\text {th }}$ ed. Pennsylvania: Saunders. Philadelphia, pp: 171-173.

3.Centers for Disease Control and Prevention (CDC) (2009): The direct medical costs of healthcare-associated infections in U.S. $\mathrm{H}$ :

https://www.cdc.gov/hai/pdfs/hai/scott costpa per.pdf.

4.Plowman R, Graves N, Griffin MA et al. (2001): The rate and cost of hospital-acquired infections occurring in patients admitted to selected specialties of a district general hospital in England and the national burden imposed. The Journal of Hospital Infection, 47:198-209.

5.Geubbels EL, Mintjes-de Groot AJ, van den Berg JM et al. (2000): An operating surveillance system of surgical-site infections in the Netherlands. Infect. Control Hosp. Epidemiol., 21:311-318.

6.Griffin FA (2005): Best-practice protocols: preventing surgical site infection. Nursing Management, 36: 22-26.

7.Dimick JB, Weeks WB, Karia RJ et al. (2006): Who pays for poor surgical quality? Building a business case for quality 
improvement. Journal of the American College of Surgeons, 202:933-937.

8.Burke JP (2003): Infection control - a problem for patient safety. N. Engl. J. Med., 348:651-656.

9.Abdel-Aziz A, El-Menyar A, Al-Thani H et al. (2013): Adherence of surgeons to antimicrobial prophylaxis guidelines in a tertiary general hospital in a rapidly developing country. Advances in pharmacological sciences, 2013:842593.

10.Gouvêa $M$, Novaes C, Pereira $D$ et al. (2015): Adherence to guidelines for surgical antibiotic prophylaxis: a review. The Brazilian Journal of Infectious Diseases, 19:517-524.

11.Knox MC and Edye M (2016): Adherence to Surgical Antibiotic Prophylaxis Guidelines in New South Wales, Australia: Identifying Deficiencies and Regression Analysis of Contributing Factors. Surgical infections, 17:203-209.

12.Craciunas $L$ and Tsampras $N$ (2014): A literature review of the current evidence for routine antibiotic prophylaxis after cervical tissue excisions. Journal of obstetrics and gynaecology : the journal of the Institute of Obstetrics and Gynaecology, 34:700-705.

13. Knebel P, Weigand MA, Buchler MW et al. (2011): Evidence-based antibiotic prophylaxis in general and visceral surgery. Der Chirurg; Zeitschrift fur alle Gebiete der operativen Medizen, 82:227-234.

14.Brand $M$ and Grieve A (2013): Prophylactic antibiotics for penetrating abdominal trauma. Cochrane Database Syst Rev., 12:70-77.

15.Koch CG, Nowicki ER, Rajeswaran J et al. (2012): When the timing is right: Antibiotic timing and infection after cardiac surgery. $\mathbf{J}$ Thorac Cardiovasc Surg., 144:931-937.e934.

16.Lewis SS, Moehring RW, Chen LF et al. (2013): Assessing the relative burden of hospital-acquired infections in a network of community hospitals. Infect Control Hosp Epidemiol., 34:1229-1230.

17.Dreher R, Tenório JL, Ferrão YA et al. (2017): Antibiotic prophylaxis with cefazolin in reducing the infection rate of nonmelanocytic skin tumors: a randomized clinical trial. European Journal of Plastic Surgery, 40:133-136.

18.Yang $X$, Xiao $X$, Wang $L$ et al. (2018): Application of antimicrobial drugs in perioperative surgical incision. Annals of clinical microbiology and antimicrobials, 17:2.
19.Imai-Kamata $S$ and Fushimi K (2011): Factors associated with adherence to prophylactic antibiotic therapy for elective general surgeries in Japan. International journal for quality in health care . journal of the International Society for Quality in Health Care, 23:167-172.

20.D'Escrivan T, Lemaire JS, Ivanov E et al. (2005): Surgical antimicrobial prophylaxis: compliance to guidelines and impact of targeted information program. Annales francaises d'anesthesie et de reanimation, 24:19-23.

21.Ng RS and Chong CP (2012): Surgeons' adherence to guidelines for surgical antimicrobial prophylaxis - a review. Australas Med J., 5:534-540.

22.Tourmousoglou CE, Yiannakopoulou E, Kalapothaki V et al. (2008): Adherence to guidelines for antibiotic prophylaxis in general surgery: a critical appraisal. The Journal of antimicrobial chemotherapy, 61:214-218.

23.Rafati M, Shiva A, Ahmadi A et al. (2014): Adherence to American society of healthsystem pharmacists surgical antibiotic prophylaxis guidelines in a teaching hospital. $\mathrm{J}$ Res Pharm Pract., 3:62-66.

24.van Kasteren ME, Kullberg BJ, de Boer AS et al. (2003): Adherence to local hospital guidelines for surgical antimicrobial prophylaxis: a multicentre audit in Dutch hospitals. The Journal of antimicrobial chemotherapy, 51:1389-1396.

25.Hohmann C, Eickhoff C, Radziwill $\mathrm{R}$ et al. (2012): Adherence to guidelines for antibiotic prophylaxis in surgery patients in German hospitals: a multicentre evaluation involving pharmacy interns. Infection, 40:131137.

26.Askarian M, Moravveji AR, Mirkhani H et al. (2006): Adherence to American Society of Health-System Pharmacists surgical antibiotic prophylaxis guidelines in Iran. Infect Control Hosp Epidemiol., 27:876-878.

27.Hosoglu S, Sunbul M, Erol S et al. (2003): A national survey of surgical antibiotic prophylaxis in Turkey. Infect Control Hosp Epidemiol., 24:758-761.

28.Lundine KM, Nelson S, Buckley, et al. (2010): Adherence to perioperative antibiotic prophylaxis among orthopedic trauma patients. Canadian journal of surgery, 53:367-372.

29.Miliani K, L'Heriteau $F$ and Astagneau $P$ (2009): Non-compliance with recommendations for the practice of antibiotic prophylaxis and risk of surgical site infection: 
Alshehri Ibrahim et al.

results of a multilevel analysis from the INCISO Surveillance Network. The Journal of antimicrobial chemotherapy, 64:1307-1315.

30.Bratzler DW and Houck PM (2004):

Antimicrobial prophylaxis for surgery: an advisory statement from the National Surgical Infection Prevention Project. Clin Infect Dis., 38:1706-1715. 